\title{
Técnicas, materiales y recursos utilizados en los procesos arteterapéuticos
}

\author{
Ma Dolores LÓPEZ MARTÍNEZ ${ }^{1}$ \\ fendi@um.es
}

Enviado: $19 / 02 / 2011$

Aceptado: 12/10/2011

\section{RESUMEN}

Los rasgos distintivos del Arteterapia se manifiestan en la conjunción de expresión artística y proceso terapéutico. En esa relación, la herramienta mediadora son las distintas técnicas y materiales plásticovisuales, que se conforman como vehículo del proceso creador y soporte de la obra plástica, posibilitando la comunicación paciente-arteterapeuta. El uso de estos medios suscita enfocarlos en dos de sus facetas esenciales: en su dimensión psicológica, incidiendo en su potencial comunicativo, expresivo, simbólico, etc.; y en su dimensión matérica, destacando sus posibilidades y cualidades materiales.

Palabras clave: Arteterapia, proceso arteterapéutico, técnicas y materiales plástico-visuales, dimensión psicológica, dimensión matérica.

\section{Referencia normalizada}

LÓPEZ MARTÍNEZ, M. D.. (2011). “Técnicas, materiales y recursos utilizados en los procesos arteterapéuticos". En Arteterapia: Papeles de arteterapia y educación artística para la inclusión social Vol.: 6. Páginas 183-191. Madrid. Servicios de publicaciones UCM.

\section{SUMARIO}

Introducción. Dimensión psicológica. Dimensión matérica. Conclusiones. Referencias bibliográficas.

\section{Techniques, materials and resources used in the art therapeutical process}

\begin{abstract}
The distinctive features of Art therapy are represented in the combination of the artistic expression and the therapeutic process. In this relation, the tools are the different plastic and visual art techniques and materials as a vehicle that makes possible the communication between patient and arttherapist. The use of these means causes to consider them in two of their essencial facets: in its psychological dimension affecting its comunicative, expressive and symbolic potencial and in its material dimension, emphasizing its possibilities and material qualities.
\end{abstract}

Keywords: Art therapy, art-therapeutic process, plastics and visuals techniques and materials, psychological dimension, material dimension.

\section{CONTENTS}

Introduction. Psychological dimension. Material dimension. Conclusions. Bibliography

\footnotetext{
${ }^{1}$ Departamento de Expresión Plástica, Musical y Dinámica. Universidad de Murcia.
} 


\section{INTRODUCCIÓN}

Las técnicas y materiales plástico-visuales son una parte esencial del proceso arteterapéutico por la función mediadora que van a establecer entre el/los paciente/s y el arteterapeuta. El uso de estos medios y la presencia de la obra plástica generan una serie de experiencias que convierten al arteterapia en una modalidad terapéutica llena de posibilidades únicas y la diferencian de las terapias con mediación verbal, al modificar la relación cliente-terapeuta y el rol tradicional atribuido a ambas figuras.

El arteterapia ha sabido adaptar tradición e innovación poniendo a disposición del arteterapeuta múltiples técnicas, materiales y recursos en sus intervenciones: desde las clásicas como el Dibujo, Pintura, Escultura o Estampación hasta las más modernas y actuales: Assemblage, Collage, Fotografía, Video, Hibridaciones y Poéticas de Intervención como Land-Art, Body-Art, Instalaciones, Performances, Acciones, Happening, etc.

La reciente integración de las nuevas tecnologías ofrece vías de innovación para explorar dentro del campo de la investigación arteterapéutica. Autores como Canter (1989), Malchiodi (2000), Samet (1989), entre otros, emplean programas informáticos de dibujo, tratamiento de imágenes o animación en tres dimensiones en sus sesiones. El uso de las nuevas tecnologías amplían las posibilidades de poder ilustrar, animar y compartir las fantasías de los participantes. "El ordenador se usa como un dispositivo para contar historias o como un títere electrónico desde el cual los clientes pueden mover fácilmente las pinturas en torno a la pantalla del ordenador para contar una historia sobre sus problemas personales". (Samet, 1989:296-297). De acuerdo con Mampaso (2005), los arteterapeutas ligados a las artes visuales deben considerar la introducción de los nuevos medios de comunicación para ampliar así el alcance terapéutico, más allá de limitarse al dibujo, la pintura y la escultura.

Los arteterapeutas también suelen incorporar en sus sesiones prácticas propias de otros ámbitos disciplinares como técnicas de: relajación, lúdicas, de visualización, de expresión musical, corporal, dramática, escritura creativa, etc. y otros recursos como la aproximación de los pacientes a las obras de arte por medio de libros, ilustraciones, visitas a galerías, museos, certámenes artísticos, invitación de artistas, etc., como tácticas a explorar con el fin de enriquecer los procesos arteterapéuticos.

El uso de estas técnicas y materiales se puede abordar en dos de sus aspectos fundamentales en el proceso arteterapéutico: en su dimensión psicológica y su dimensión matérica. Ambos aspectos no suponen una visión dicotómica, ya que no se pueden separar. Por lo tanto, se focalizarán aquellos rasgos más destacables de cada una de esas dimensiones.

\section{DIMENSIÓN PSICOLÓGICA}

La experimentación matérica: colores, trazos, texturas, etc., y el valor simbólico de las imágenes creadas permiten a su autor la autoexploración semántica de sus emo- 
ciones y pensamientos, desde la multiplicidad de perspectivas que los medios plástico-visuales pueden llegar a ofrecer. Las cualidades específicas de la pintura, el modelado, el dibujo, etc., reflejan, sostienen y transforman las experiencias psicológicas hacia un cambio saludable con el acompañamiento de un arteterapeuta experto.

Los medios plásticos, a través de sus signos, sirven de médium a una inmensa categoría de representaciones, no comparables a las del pensamiento discursivo, pero igualmente eficaces y tan reveladores como los aportados por los medios verbales. Incluso pueden, en un diálogo metalingüístico, ampliar la capacidad expresiva y comunicativa en situaciones especiales, provocadas por bloqueos, falta de dominio lingüístico, inhibiciones o disfunciones físicas o psíquicas.

Desde un punto de vista psicoanalítico, el uso de medios plástico-visuales aumentan las opciones expresivas y de autoconocimiento de contenidos velados por el consciente. Cuando se pinta o modela, es más fácil acceder a la realidad interna que con las palabras. Debilita las defensas y relaja a la persona, facilitando la expresión de su intimidad.

A través de la ley de la materia, el individuo puede observarse a sí mismo, figurar sus conflictos y examinarlos desde un plano que es interno y externo simultáneamente. $\mathrm{Al}$ enfrentarse a los problemas técnicos y plásticos de la tarea, indirectamente la persona amplía su conciencia sobre su actitud ante la vida.

Durante la realización de la obra plástica, el paciente mantiene un diálogo intuitivo y sensitivo con los materiales que van dando forma a su autoexpresión. En ese acto creador la atención queda absorbida por la actividad, siendo ese estado denominado "Experiencia óptima o Flow".

La manipulación de estos medios proporciona también un distanciamiento. La teoría "Aesthetic distance" se centra en la noción de distancia que permite examinar los límites de nuestras relaciones con los demás hasta conseguir una mayor flexibilidad. En los individuos sobredistanciados, con límites muy rígidos con ellos mismos y con los demás, la realización de la tarea plástica puede potenciar el compromiso, mientras que en los individuos hipodistanciados, que se relacionan demasiado rápidamente con los demás y se agobian con sus vivencias, puede ayudarles a alejarse, a objetivar sus sentimientos de forma más desapasionada.

Por otra parte, la intervención con medios artísticos es menos invasiva, en contraste con otros tratamientos más convencionales, utilizados en contextos hospitalarios, psiquiátricos, penitenciarios, etc., ya que ayudan a superar las inhibiciones verbales al constituir espacios creativos y de juego, que favorecen el desarrollo y maduración emocional, social y cognitivo de la persona.

Los materiales plásticos permiten la permanencia de la obra, más allá de cada sesión, proporcionan la continuidad de momentos o experiencias efímeras del sujeto. Permite a la persona que no puede hablar, volver inmediatamente sobre lo realizado cuando se sienta capaz de observarlo. Evaluarlo o analizarlo en cualquier mo-

\footnotetext{
${ }^{2}$ Concepto acuñado por Csikszentmihalyi (2004).

${ }^{3}$ Teoría aplicada por la autora Landy (1996).
} 
mento de la terapia, al actuar como un registro de lo aportado por la persona. La visión retrospectiva del trabajo plástico a lo largo de la terapia permite observar toda la evolución.

\section{DIMENSIÓN MATÉRICA}

Los medios artísticos en su dimensión matérica poseen una serie de cualidades físicas, de las que el arteterapeuta debe tener conocimientos suficientes. Si este mantiene una relación constante con las actividades artísticas podrá experimentar con mayor facilidad la conexión sensorial con los materiales para llegar a vivenciar lo que transmiten, evocan o propician.

Varias autoras han planteado cuestiones sobre los criterios de selección de las técnicas y los materiales artísticos más adecuados, según el tipo de patología o problema. Landgarten (1987) discute sobre los beneficios terapéuticos que pueden aportar cada uno de estos medios, estableciendo una clasificación según el nivel de control técnico de sus propiedades, a la que llama Media Dimension Variables $(M D V)$, (tabla $\left.\mathrm{n}^{\circ} 1\right)$. La autora afirma que, de acuerdo con este punto, se puede elevar o bajar el estado afectivo del cliente, influir en su libertad de expresión y engañar las defensas.

Tabla n $^{0}$ 1. Clasificación de Landgarten según el nivel de control técnico de cada medio plástico-visual

\begin{tabular}{|c|c|c|c|}
\hline & $\begin{array}{l}\text { Control Alto (Grado de } \\
\text { dificultad baja) }\end{array}$ & $\begin{array}{l}\text { Control Medio (Grado de } \\
\text { dificultad medio) }\end{array}$ & $\begin{array}{l}\text { Control Bajo } \\
\text { (Grado de dificul- } \\
\text { tad alto) }\end{array}$ \\
\hline Gráfico & $\begin{array}{l}\text { - Lápiz de Grafito (dureza } \\
\text { media) } \\
\text { - Lápices de colores } \\
\text { - Lápiz Pasta } \\
\text { - Plumón }\end{array}$ & $\begin{array}{l}\text { - Cera blanda } \\
\text { - Pastel graso }\end{array}$ & $\begin{array}{l}\text { - Carboncillo } \\
\text { - Tinta China } \\
\text { - Pastel seco } \\
\text { - Tiza }\end{array}$ \\
\hline Pictórico & $\begin{array}{l}\text {-Témperas } \\
\text {-Pinceles gruesos y brochas }\end{array}$ & $\begin{array}{l}\text { - Pintura de dedos } \\
\text { - Lápices acuarelables } \\
\text { - Acrílicos } \\
\text { - Pastel graso con trementina } \\
\text { - Sprays }\end{array}$ & $\begin{array}{l}\text { - Acuarela } \\
\text { - Óleo } \\
\text { - Rodillo } \\
\text { - Espátula } \\
\text { - Esponja }\end{array}$ \\
\hline Tridimensional & $\begin{array}{l}\text { - Plastilina } \\
\text { - Arcilla o barro } \\
\text { - Pasta de sal }\end{array}$ & $\begin{array}{l}\text { - Cartón pluma } \\
\text { - Greda, Yeso } \\
\text { - Material de desecho } \\
\text { - Papel Maché }\end{array}$ & $\begin{array}{l}\text { - Talla } \\
\text { - Gubias } \\
\text { - Moldes }\end{array}$ \\
\hline Otros & $\begin{array}{l}\text { - Revistas y papeles para } \\
\text { collages }\end{array}$ & - Costura y estampado & $\begin{array}{l}\text { - Grabado } \\
\text { - Video } \\
\text { - Fotografía } \\
\text { - Ordenadores }\end{array}$ \\
\hline
\end{tabular}

Wadeson (1980) y Dalley (1987) mantienen una opinión parecida. Para Wadeson, los materiales con un grado de dureza alto son más fáciles de controlar. Respecto a los materiales blandos o fluidos percibe en la mayoría de sus pacientes una 
mayor tolerancia y aceptación a la incertidumbre. También expone que los objetivos planteados, durante las sesiones, y las características de los usuarios condicionan la elección de los materiales y técnicas plástico-visuales, por parte del arteterapeuta. Cuando se realizan ejercicios de libre asociación o para favorecer la comunicación grupal o familiar, los medios rápidos como pasteles o crayones son los más indicados. Si se pretende potenciar la espontaneidad y creatividad del individuo hay que proporcionar gran variedad de materiales donde se pueda experimentar tamaños, formatos, propiedades, formas distintas de aplicarlos. En el caso de personas con discapacidades físicas, niños muy pequeños o ancianos poco autónomos, se pueden ofrecer materiales de manipulación sencilla como lápices de colores gruesos, ceras o pasteles. Brindar la oportunidad de poder mancharse con las pinturas $u$ otros utensilios puede ser revitalizante para un individuo severamente inhibido.

Tras sus experiencias clínicas, Dalley (1987) ha observado que la pintura permite una expresión afectiva más fluida, mientras que los trazos dibujados a lápiz suelen implicar más control.

Kagin y Lusebrink (1978) proponen un esquema donde clasifican las propiedades físicas de los medios plásticos y visuales según su poder evocativo. (Ver tabla $\mathrm{n}^{\mathrm{o}} 2$ ). Cuanto mayor sea la fluidez del medio, más estados emocionales evocará. Los medios más sólidos tienden a contener las emociones y a procesar la información de forma cognitiva.

\section{Tabla ${ }^{0}$ 2. Clasificación de las propiedades de los medios artísticos pro- puesta por Kagin y Lusebrink}

\begin{tabular}{|c|c|}
\hline Medios Fluidos $\leftarrow$ & Medios Sólidos \\
\hline Acuarelas sobre papel húmedo & Escultura de \\
\hline Pintura de dedos & piedra/madera \\
\hline sobre papel húmedo & Arcilla/Plastilina \\
\hline Pintura sobre soportes secos & Lápices de colores \\
\hline Pasteles secos & Collages \\
\hline Pasteles grasos & Lápices \\
\hline $\begin{array}{l}\text { Experiencia } \leftarrow \\
\text { Afectiva }\end{array}$ & $\rightarrow \quad \begin{array}{c}\text { Experiencia } \\
\text { Cognitiva }\end{array}$ \\
\hline
\end{tabular}


Kramer (1971) presta una atención especial a las diversas formas de manipular los materiales. La autora establece una clasificación, en la que distingue cinco maneras de utilizar los medios artísticos y su relación con las posibles reacciones psicológicas, que pueden llegar a suscitar en los pacientes:

- Precursory Activity, son acciones diseñadas para explorar las propiedades físicas de cada material y así experimentar las sensaciones perceptivas, sin llegar a la creación concreta de configuraciones simbólicas. Garabatear, tocar, esparcir y salpicar pintura o amasar material dúctil se incluyen en esta categoría por sus potenciales estimulantes.

- Chaotic Discharge, se trata de la utilización destructiva de los materiales para descargar emociones negativas intensas como la rabia, la angustia o la impotencia. Se puede utilizar la técnica de Dripping, aplastar o golpear materiales blandos, rasgar papeles, romper las obras realizadas y construir con los restos algo nuevo, etc., con una finalidad inminentemente catártica.

- Art in the Service of Defense, son producciones que surgen, cuando la persona realiza gestos gráficos convencionalmente estereotipados, como copiar, remarcar, dibujar siempre lo mismo, etc. Señalan que el individuo tiene dificultad en expresar su personalidad abiertamente e incentivan el diálogo sobre aquellos aspectos causantes de bloqueos.

- Pictographs, son dibujos que reemplazan o complementan a las palabras como, por ejemplo, un diálogo dibujado entre paciente y terapeuta. Sólo son comprensibles al observador externo si el autor o el terapeuta explican su significado y el contexto en el que surgieron.

- Formed Expression, son producciones o actuaciones que contienen un nivel simbólico complejo, cargadas emocionalmente. Propician la autoexpresión y la comunicación, tanto con el terapeuta como con cualquier observador externo.

Otros autores se han centrado en las propiedades terapéuticas de materiales, medios y técnicas concretos. ${ }^{4}$

En líneas generales, Polo Dowmat (2003) considera que las técnicas, materiales y recursos ofrecidos en arteterapia deben poseer las siguientes características:

-Que sean de realización sencilla para ser abordadas con éxito por toda clase de personas, incluso aquellas no experimentadas plásticamente.

\footnotetext{
${ }^{4}$ Amari (1986); Anderson (1995); Barnaby (1998); Brock (1991); Elkis-Abuhoff, Goldblatt, Gaydos, Corrato (2008); Henley (2002), Sholt y Gavron (2006), describen en sus trabajos cómo las cualidades físicas del barro revelan material inconsciente, facilitan la expresión de emociones, provocan procesos regresivos y catárticos, desarrollan la capacidad háptica y estimulan la comunicación verbal.

Canal y Ramiro (2004), Fryrear y Corbit (1992, 2005), Glover-Graf y Miller (2006), Krauss y Fryrear (1983), Weiser (2004), focalizan su atención sobre las técnicas fotográficas dentro de un encuadre arteterapéutico.

Berger (1978), Dowrick y Biggs (1983), Fryrear y Fleshman (1981), Helveil (1983), Hinz y Ragsdell (1990), Mampaso (2005), han realizado intervenciones en videoterapia; Chilton (2007), con libros de autor; Mulholland (2004), sobre personajes de cómics e ilustraciones y Kaufman (1996) presenta una experiencia con trabajos tridimensionales construidos con cajas de cartón.
} 
-Que propicien la concreción de una imagen eficaz y comunicativa de sus significantes, para su posterior lectura y análisis.

-Que permitan una alfabetización estética, especialmente del arte contemporáneo por ser un producto de nuestro tiempo con gran poder comunicativo de emociones e ideas.

-Que permitan el goce y la satisfacción por el trabajo creativo, favoreciendo la confianza, la autoestima y el sentido de realización personal.

-Que se adapten, por su economía de medios, a los generalmente exiguos presupuestos institucionales e incluso individuales, destinados a este tipo de actividades. (Polo Dowmat ,2003:19).

El terapeuta debe ser sensible a las necesidades individuales, evitar los materiales frustrantes o que resulten difíciles de manejar y dar seguridad con una aproximación a las cualidades de cada medio. A veces se propone traer el material con una historia implícita que también el grupo puede acoger.

La variedad de materiales facilita el encuentro con lo que más guste y el arteterapeuta debe facilitar dicho encuentro.

\section{CONCLUSIONES}

El uso de técnicas y medios plástico visuales presentan un potencial extraordinario en el proceso arteterapéutico desde sus dimensiones tanto psicológica como matérica.

Cada técnica plantea una serie de retos diferentes, por lo tanto, es importante que los participantes tengan la oportunidad de trabajar con la máxima variedad posible. Si la técnica siempre es la misma, los sujetos tenderán a repetir comportamientos. En cambio, con la variación cíclica de los medios artísticos, se ofrece la posibilidad de desbloquear reacciones y transformar actitudes frente a todas las situaciones que se vayan experimentando en el setting, incluso aquellas que, en un principio, puedan provocar rechazo.

El uso de las técnicas plásticas supone un poder de adaptación de la imaginación a los materiales que presentan posibilidades particulares, limitadas por una parte, pero llenas de recursos insospechados. Por lo tanto, la persona no debe convertirse en prisionero de un procedimiento, la técnica no ha de aplicarse como un código rígido y definitivo, ya que perdería su valor fundamental, su carácter de descubrimiento. Lo importante es que siempre prevalezca en el trabajo plástico la personalidad del individuo.

Por otra parte, por ricas que sean las técnicas artísticas, solamente tendrán un valor terapéutico si proporcionan una vía de comunicación entre paciente y terapeuta, incentivada a través del uso del material adecuado. Es fundamental que los arteterapeutas conozcan las múltiples posibilidades que ofrecen la gran variedad de materiales y técnicas plásticas y/o visuales en un setting terapéutico. Para adecuar los objetivos de sus demandantes los terapeutas artísticos tendrán en cuenta las implicaciones físicas y psíquicas que los materiales contienen en sí mismos. 
Según la bibliografía revisada algunos arteterapeutas siguen criterios a la hora de seleccionar los medios artísticos. Se rigen por el nivel de control técnico, su carga simbólica, lo que evoca la manipulación de las cualidades matéricas, el grado de bienestar, etc. Sin embargo, resulta una labor compleja clasificar los materiales según el tratamiento aplicado y la gran diversidad de usuarios existentes.

También se constata la escasez de investigaciones científicas que especifiquen con rigor aspectos que orienten la selección de los materiales y técnicas. Esta ausencia deja abiertas interesantes vías de investigación, cuyas aportaciones permitirían llenar un vacío y ser de gran utilidad para hacer más eficaces los tratamientos arteterapéuticos. 


\section{REFERENCIA BIBLIOGRÁFICAS}

CANTER, D. S. (1989). Art therapy and computers. Advances in Art Therap. New York, Wiley \& Sons.

DALLEY, T. (Ed.) (1987). El arte como terapia. Barcelona: Herder

KAGIN, S. y LUSEBRINK, V. (1978). The expressive therapies continuum. En Journal of Art Psychotherapy, 5, 171-179.

KRAMER, E. (1971). Art as therapy with children. New York, Schocken Books, Inc.

LANDGARTEN, H. B, (1987). Family art psychotherapy: A clinical guide and casebook. New York, Brunner/ Mazel Publishers.

MALCHIODI, C.A. (2000). Art therapy and Computer technology: A virtual Studio of Possibilities. London: Jessica Kingsley.

MAMPASO MARTÍNEZ, A. (2005). La video- animación: Aplicaciones en los campos de desarrollo social y comunitario, la educación artística y el arte-terapia. Tesis para optar al grado de Doctor. Departamento de Comunicación Audiovisual y Publicidad I. Facultad de Ciencias de la Información. Universidad Complutense de Madrid, España.

POLO DOWMAT, L.C. (2003). Técnicas plásticas del arte moderno y la posibilidad de su aplicación en arte terapia. Tesis para optar al grado de Doctor. Departamento de Didáctica de la Expresión Plástica. Facultad de Bellas Artes. Universidad Complutense de Madrid. España.

SAMET, D. (1989). Art therapy and computers.En: Wadeson, H., Durking, J., Perach, D. (Eds.), Advances in Art Therapy, (pp.296-317). Canadá: Wiley.

WADESON, H. (1980). Art Psichotherapy. Nueva York: Wiley. 